\title{
Solidification Structures of Inconel 718 with Microalloying Elements
}

\author{
Y.Murata, M.Morinaga, N.Yukawa, H.Ogawa and M.Kato \\ Department of Production Systems Engineering, \\ Toyohashi University of Technology, \\ 1-1 Hibarigaoka, Tempaku-cho, Toyohashi 441, JAPAN
}

\begin{abstract}
The microalloying effects on the solidification structure of Inconel 718 were examined by means of differential thermal analysis, optical microscopy and scanning electron microscopy, in order to elucidate the mechanism of the macrosegregation in the alloy. The solidification and precipitation sequence of Inconel 718 was found to be characterized by the following five reactions; (1) the proeutectic $\gamma$ reaction at about $1360^{\circ} \mathrm{C}$, (2) the $\gamma+\mathrm{MC}$ cutcctic reaction at about $1290^{\circ} \mathrm{C}$, (3) the $\gamma+$ Laves phase eutectic reaction at about $1160^{\circ} \mathrm{C}$, (4) the $\delta$ phase precipitation reaction in the $\gamma$ phase at about $1145^{\circ} \mathrm{C}$, and (5) the $\gamma^{\prime}$ and $\gamma^{\prime \prime}$ precipitation reaction in the $\gamma$ phase at about $1000^{\circ} \mathrm{C}$. By combining this result with the analysis of the solute distributions in the ESR ingots, the mechanism for the occurrence of the freckles was proposed in Inconel 718.
\end{abstract}

\footnotetext{
Superalloys 718, 625,706 and Various Derivatives Edited by E.A. Loria

The Minerals, Metals \& Materials Society, 1994
} 


\section{Introduction}

Inconel 718 is a wrought nickel-based superalloy used for the disks, the combustion cans and the other gas turbine components. The size of the ingots prepared mainly by VAR (Vacuum Arc Remelting) and ESR (Electroslag Remelting), has recently been increasing in response to the necessity of the scaling-up of the components. However, because of the existence of a high concentration of refractory elements in the alloy, the solutes tend to segregate during solidification. This is a serious problem of long standing, particularly in large ESR ingots. For example, the appearance of the freckles which are sort of the macrosegregation in the alloy is troublesome, because compositional inhomogeneity due to the segregation remains even after forging, resulting in deterioration of the mechanical properties of the alloy. In addition, there has been a trial to modify Inconel 718 by replacing $\mathrm{Nb}$ and $\mathrm{Fe}$ with Ta and $\mathrm{Co}$ in order to improve the high temperature properties, and the so-called Rene' $220 \mathrm{C}$ has been developed[1].

Thus, it is very important to elucidate alloying effects of various elements on the solidification microstructures. Most of the previous publications, however, have been concerned in the precipitation behaviour of the Laves and the $\gamma^{\prime \prime}$ phases in the wrought alloy[2-7], and only a few ones have referred to the solidification sequence[8,9]. Recently, the solidification and precipitation sequence of Inconel 718 has been revealed by a series of the experiments including the differential thermal analysis (DTA) and the microstructural observations[10].

In the present study, in order to get some guidance for diminishing the segregation and also for improving the weldability, microalloying effects were investigated on the solidification structure of Inconel 718.

\section{Experimental Procedure}

The present experiments were performed in a similar way as our previous experiments [10]. Namely, there were following three steps involving in this experiments : (1) microalloying of specific elements into the mother alloy by using a tri-arc furnace, (2) performing DTA measurements with both the mother alloy and the microalloyed ones, and (3) analyzing the microstructures after DTA measurements.

The chemical composition of the mother alloy is shown in Table 1. The compositional range of the Aerospace Material Specification (ASM) and the contents of microalloying elements are also shown in the same table. The microalloying elements selected were $\mathrm{Mo}, \mathrm{Nb}, \mathrm{Ti}, \mathrm{Al}$

Table 1 Chemical composition of Inconel 718 and the amounts of microalloying elements.

\begin{tabular}{|c|c|c|c|c|c|c|c|c|c|c|}
\hline & $\mathrm{Cr}$ & $\mathrm{Ni}$ & Mo & $\mathrm{Nb}$ & $\mathrm{Ti}$ & $\mathrm{Al}$ & $\mathrm{C}$ & $\mathrm{Mn}$ & $\mathrm{Si}$ & $\mathrm{Fe}$ \\
\hline \multirow[t]{8}{*}{ Inconel 718} & 20.28 & 52.02 & 1.89 & 2.96 & 1.31 & 0.71 & 0.14 & 0.13 & 0.10 & bal. \\
\hline & - & - & $+1.0^{*}$ & - & - & - & - & - & - & - \\
\hline & - & - & - & +0.5 & - & - & - & - & - & - \\
\hline & - & - & - & +1.0 & - & - & - & - & - & - \\
\hline & - & - & - & +2.0 & - & - & - & - & - & - \\
\hline & - & - & - & - & +0.5 & - & - & - & - & - \\
\hline & - & - & - & - & - & +0.2 & - & - & - & - \\
\hline & - & - & - & - & - & +0.04 & - & - & - & - \\
\hline AMS & $\begin{array}{c}19.00 \\
i \\
23.26\end{array}$ & $\begin{array}{c}49.50 \\
⿱ 亠 \\
53.94\end{array}$ & $\begin{array}{c}1.70 \\
? \\
3.41\end{array}$ & $\begin{array}{c}2.97 \\
? \\
1.98\end{array}$ & $\begin{array}{c}0.79 \\
? \\
1.38\end{array}$ & 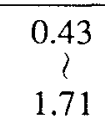 & $<0.38$ & $<0.37$ & $<0.72$ & bal. \\
\hline
\end{tabular}

* For example, +0.1 for Mo means that the total amount of Mo content in the microalloyed alloy is $2.89 \mathrm{wt} \%$. 
and C. For every microalloyed specimen, a button ingot of about $15 \mathrm{~g}$ was prepared by a tri-arc furnace in a purified argon gas atmosphere.

The DTA measurements were carried out with the samples of about $0.2 \mathrm{~g}$ by cooling at a constant rate of $5^{\circ} \mathrm{C} / \mathrm{min}$ in the temperature range from $900^{\circ} \mathrm{C}$ to $1450^{\circ} \mathrm{C}$. The onset temperature of phase transition was determined from a peak on the DTA thermogram following the method described in ref.11, and it was denoted as $\mathrm{Pi}_{\mathrm{i}}$.

Furthermore, the chemical compositions in several portions of an ESR ingot were examined by using the EPMA/EDX method in order to clarify the mechanism of the freckle formation in Inconel 718. For comparison, similar experiments were performed with Waspaloy.

\section{Results and Discussion}

\section{Solidification and precipitation sequence}

The solidification sequence and the onset temperatures of phase precipitation are shown in Fig.1. In the figure, the results reported by Ballantyne et al.[8] is also presented for comparison. Both the $\delta$ and the $\gamma^{\prime \prime}\left(+\gamma^{\prime}\right)$ phase transitions were observed in our study but not in their study. Also, there was a small difference in the temperatures of the $\gamma$ and the MC formation. This might be due to a small difference in the alloy composition between our heat and theirs, as is shown in Fig.1.

The solidification microstructure of Inconel 718 is shown in Fig.2. Dark area containing some white massive phase and MC carbide can be seen between the dendrites. A SEM micrograph taken from the dark area is shown in Fig.3. The plate-like phase is $\delta\left(\mathrm{Ni}_{3} \mathrm{Nb}\right)$ $[8,10]$, an the very fine precipitates surrounding the massive phase are $\gamma^{\prime \prime}\left(\mathrm{DO}_{22}\right)$ and $\gamma^{\prime}\left(\mathrm{Ll}_{2}\right)$ $[4,5,10]$. Also, the massive phase may consist of two kinds of the Laves phases, $\mathrm{Fe}_{2} \mathrm{Nb}$ and $\mathrm{Cr}_{2} \mathrm{Nb}$, both having the $\mathrm{C} 14$ type structure[10].

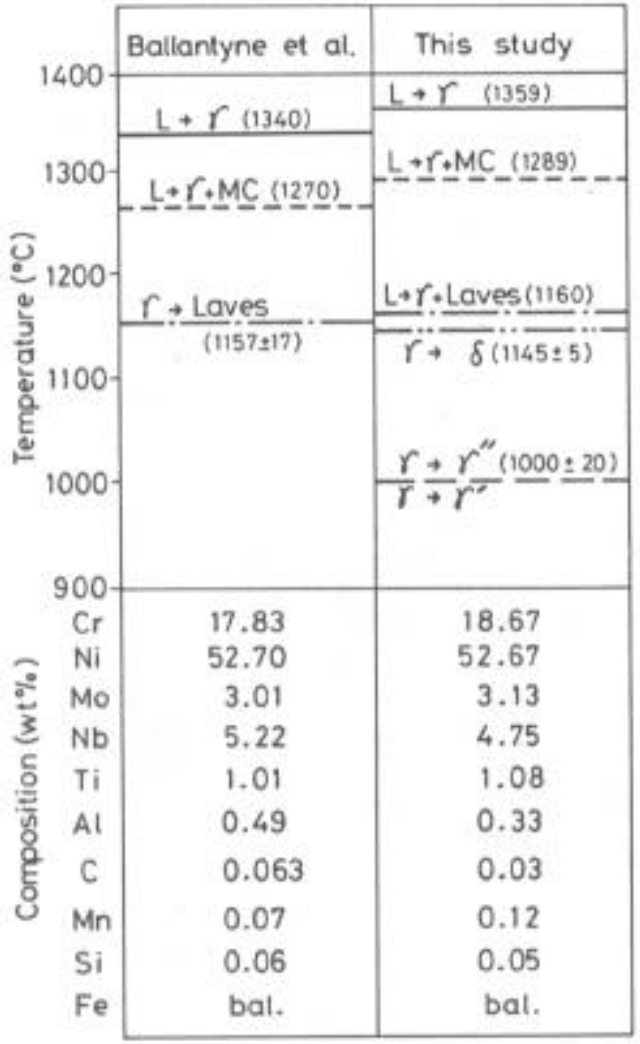

Fig.1 Solidification and precipitation sequence of Inconel 718.

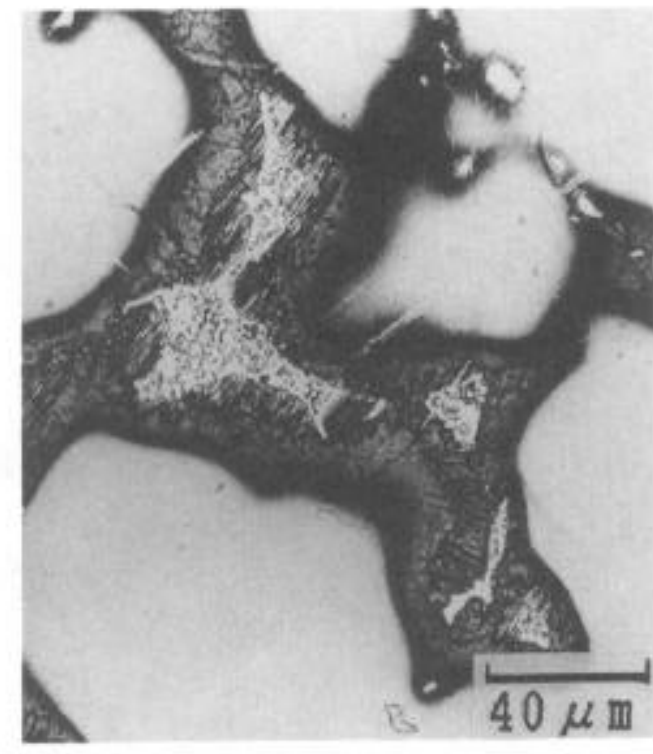

Fig.2 Microstructure of Inconel 718 observed after DTA measurements. 


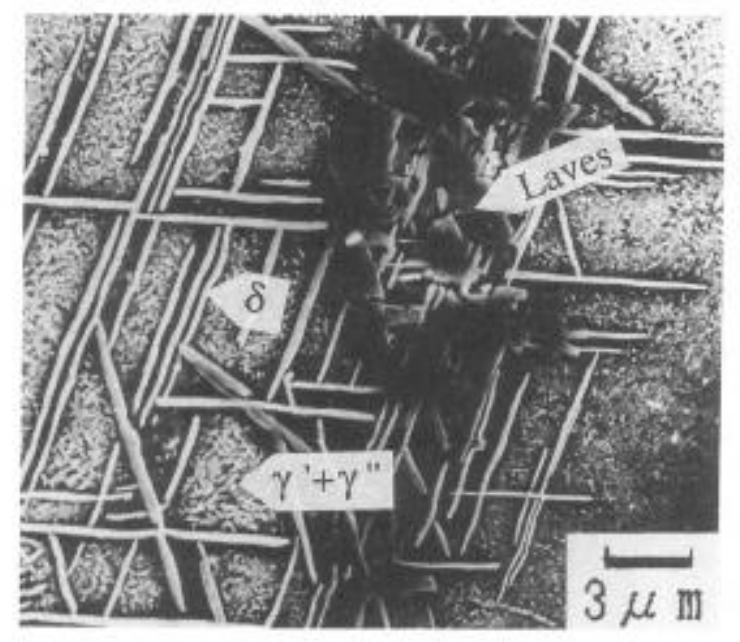

Fig.3 SEM image of Inconel 718 observed after DTA measurements.
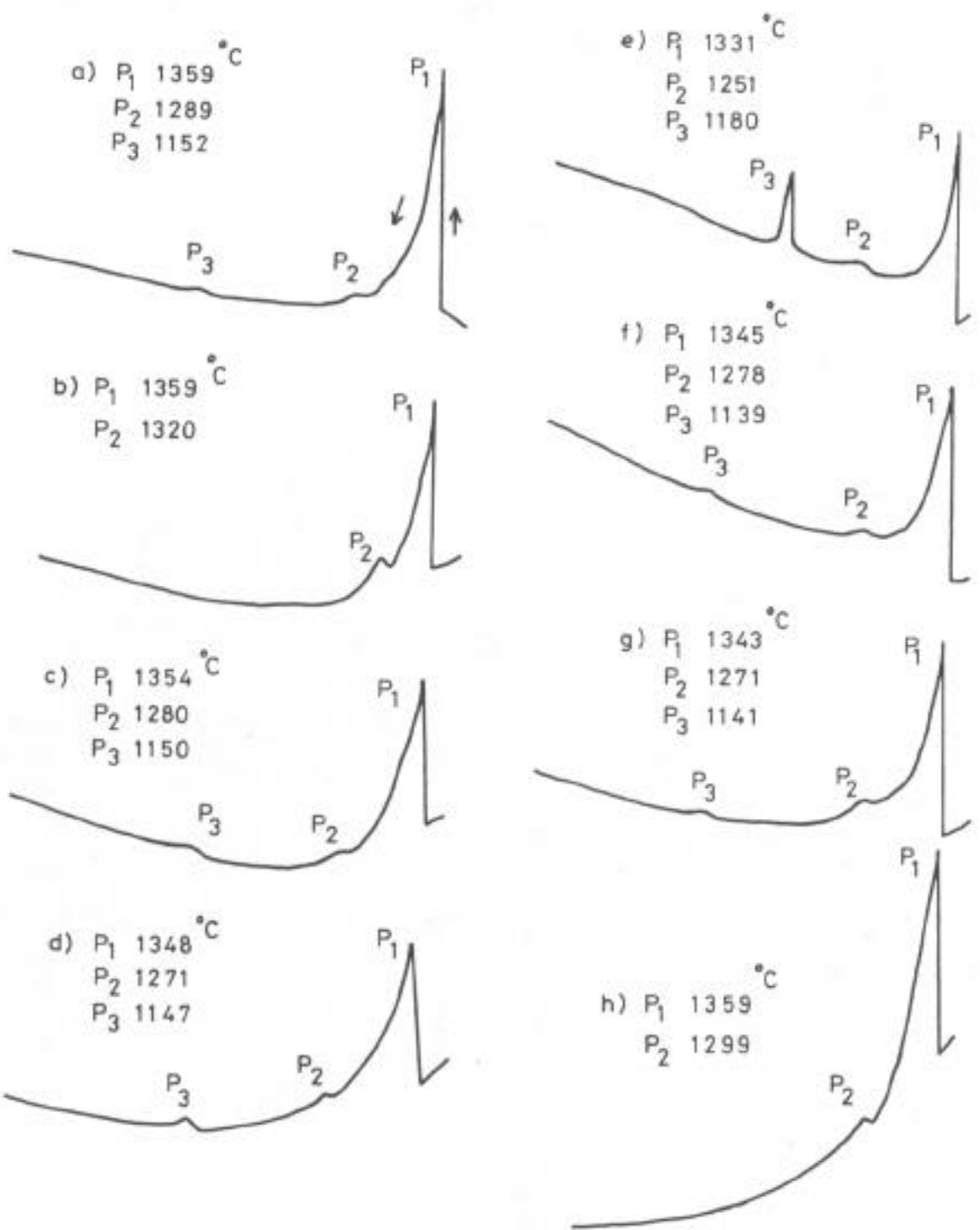

Fig 4 DTA curves of the mother alloy and the microalloyed ones;
(a) mother alloy,
(b) $+0.04 \mathrm{wt} \% \mathrm{C}$,
(c) $+0.5 \mathrm{wt} \% \mathrm{Nb}$
(d) $+1.0 \mathrm{wt} \% \mathrm{Nb}$,
(e) $+2.0 \mathrm{wt} \% \mathrm{Nb}$,
(f) $+0.2 \mathrm{wt} \% \mathrm{Al}$,
(g) $+1.0 \mathrm{wt} \% \mathrm{Mo}$,
(h) $+0.5 \mathrm{wt} \% \mathrm{Ti}$. 


\section{Microalloying experiments}

Typical DTA cooling curves of Inconel 718 and the microalloyed specimens are shown in Fig.4. In Inconel 718, three peaks appeared between $1359^{\circ} \mathrm{C}$ and $1152^{\circ} \mathrm{C} . \quad \mathrm{P} 1$ is the liquidus where the primary crystallization takes place (see Fig.1), $\mathrm{P}_{2}$ and $\mathrm{P}_{3}$ peaks are associated with the formation of the MC carbide and the Laves phase, respectively [10]. In the microstructure (Fig.2), MC carbide, Laves, $\delta, \gamma^{\prime}$ and $\gamma^{\prime \prime}$ phases were present in the as-solidified Inconel 718. However, only three peaks appeared in the DTA thermogram. The precipitation reactions and the temperatures shown in Fig.1 were determined by a series of experiments; the slowly-cooled samples were reheated up to above and below a specific temperature, followed

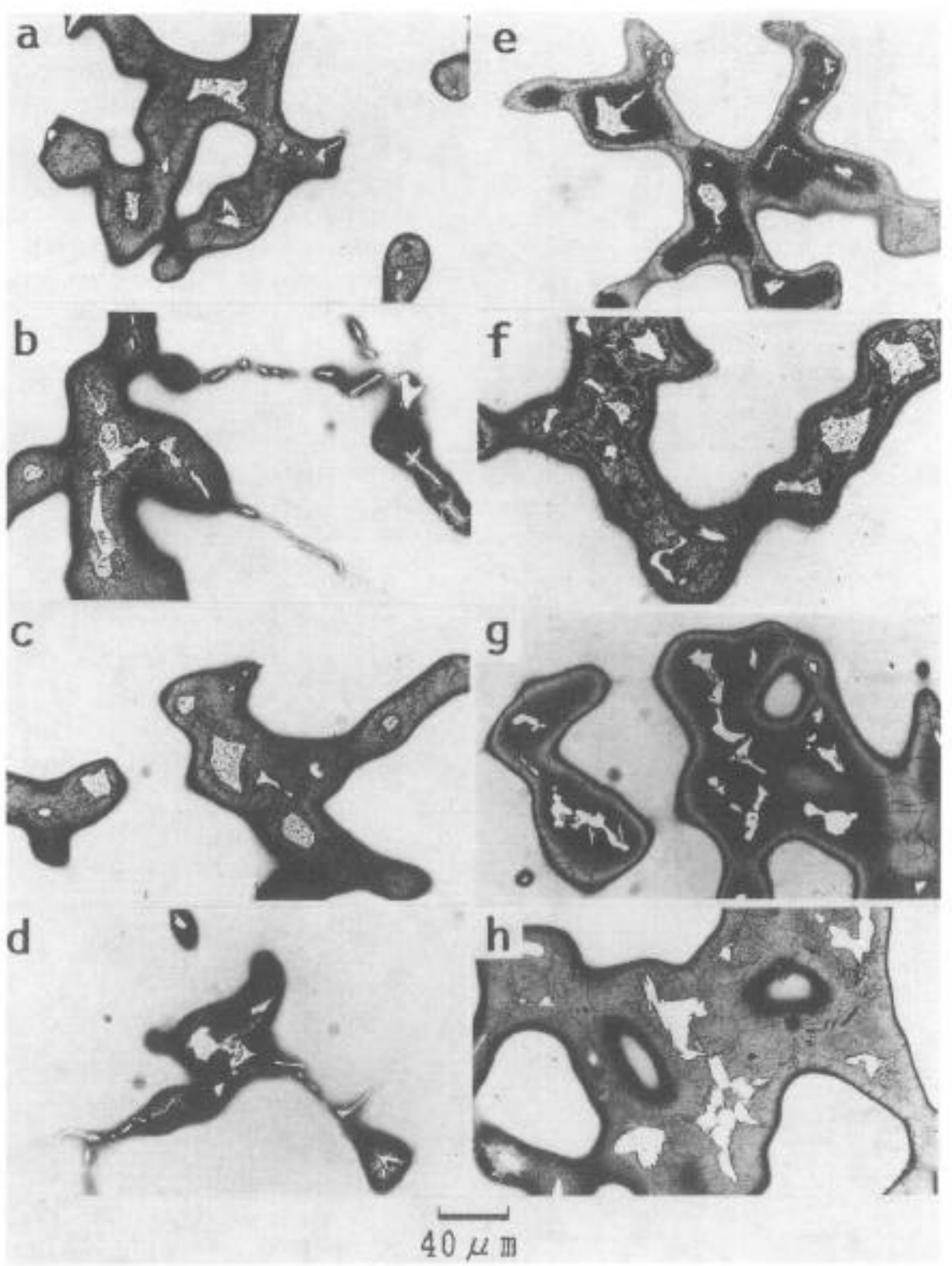

Fig.5 Microstructures of the mother alloy and the microalloyed ones observed after DTA measurements;
(a) mother alloy,
(b) $+0.04 \mathrm{wt} \% \mathrm{C}$,
(c) $+0.5 w t \% \mathrm{Nb}$,
(d) $+1.0 \mathrm{wt} \% \mathrm{Nb}$,
(e) $+2.0 \mathrm{wt} \% \mathrm{Nb}$,
(f) $+0.2 \mathrm{wt} \% \mathrm{Al}$,
(g) $+1.0 \mathrm{wt} \% \mathrm{Mo}$,
(h) $+0.5 \mathrm{wt} \% \mathrm{Ti}$. 
by quenching into water, and then microstructures were examined in detail[10].

The effects of the microalloying elements on the onset temperatures and the peak height of DTA curves are summarized as follows: (1) the peak height of $\mathrm{P}_{2}$ increased by the addition of $0.04 \% \mathrm{C}$, but that of $\mathrm{P}_{3}$ decreased reversely (curve (b)), (2) the $\mathrm{P}_{3}$ peak was enhanced by the addition of $\mathrm{Nb}$ (curves (c), (d) and (e)), (3) the peak height of $\mathrm{P}_{3}$ increased slightly by the addition of $0.2 \% \mathrm{Al}$ (curve (f)), (4) the Mo addition scarcely changed the DTA curve of the mother alloy (curve $(\mathrm{g})$ ), (5) the peak height of $\mathrm{P} 3$ decreased considerably by the addition of $0.5 \% \mathrm{Ti}$ (curve $(\mathrm{h}))$.

Fig. 5 shows the microstructures of the microalloyed specimens after DTA measurements. The figure marks of (a) (h) in Fig.5 correspond to those in Fig.4. For example, the microstructure in the mother alloy is shown in (a). Compared to this micrograph, microstructural changes with microalloying are summarized as follows : (1) the amount of MC carbide increased in the grain boundaries by the $\mathrm{C}$ addition, (2) the amount of Laves phase

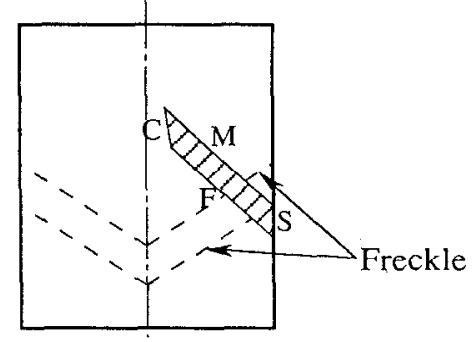

ESR ingot
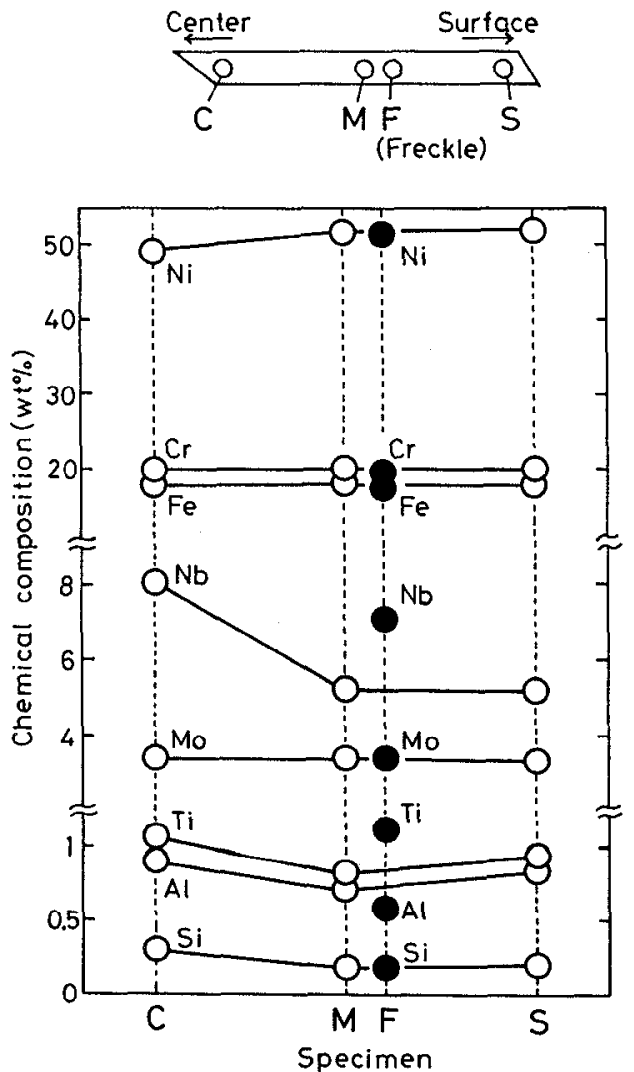

Fig.6 Comparison of chemical compositions at various portions in an ESR ingot of Inconel 718. increased remarkably by the $\mathrm{Nb}$ addition, (3) the dark area, in which both the $\gamma^{\prime}$ and the $\gamma$ " phase precipitate, increased but the amounts of the MC carbide and the Laves phase decreased by the $\mathrm{Ti}$ addition. Therefore, microalloying of $\mathrm{Nb}, \mathrm{Ti}$ and $\mathrm{C}$ into Inconel 718 affected considerably to the solidification microstructures.

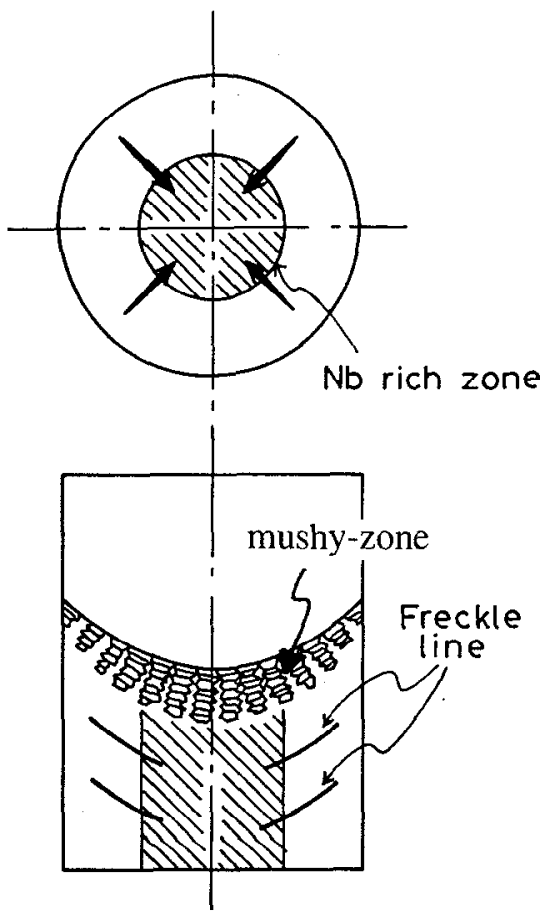

Fig.7 Schematic illustration of freckling in an ESR ingot of Inconel 718. 


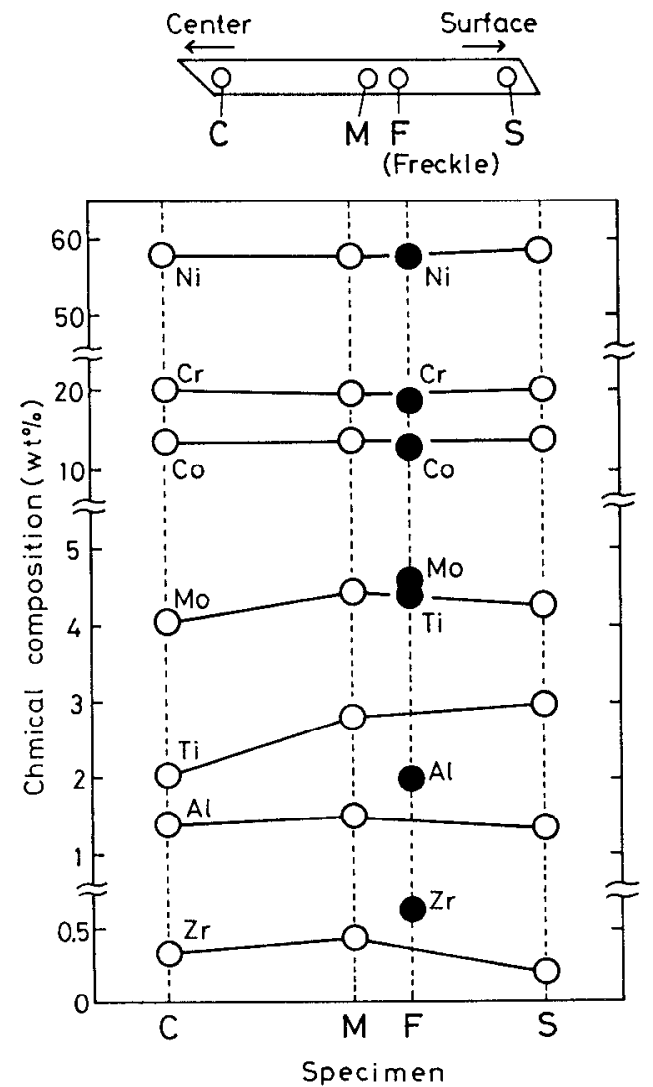

Fig. 8 Comparison of chemical compositions at various portions in an ESR ingot of Waspaloy.

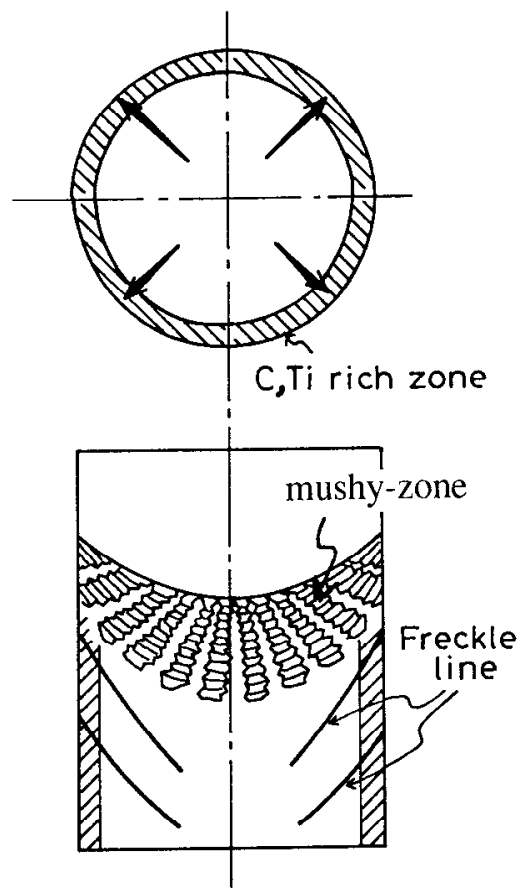

Fig.9 Schematic illustration of freckling in an ESR ingot of Waspaloy.

Mechanism of the freckle formation

Fig.6 shows the chemical compositions of a specimen cut from an ESR ingot in which the freckles existed. At the top of the figure, the location where the specimen was cut, is shown by a schematic drawing of the ESR ingot. The marks, "C", "M", "F" and "S", indicate the center-, the middle-, the freckle- and the surface-portion of the ingot, respectively. From the figure, it was found that $\mathrm{Nb}$ was enriched in the central-portion. Also, both $\mathrm{Nb}$ and $\mathrm{Al}$ were enriched but $\mathrm{Al}$ was deficient in the freckle-portion. In particular, the $\mathrm{Nb}$ level in the freckle-portion was higher by $2 \sim 3 \mathrm{wt} \%$ than that in the middle- and the surface-portion. But any significant segregation was not observed in other alloying elements, even though the Ti level was slightly different from that in other portions.

On the basis of this experimental result as well as the solidification sequence and the results of the microalloying experiments, an explanation was given of the freckle formation in ESR ingots. During ESR processing, a mushy zone formed at the solid-liquid interface has a curvature as is shown in Fig.7. The Nb-rich phases such as the $\delta\left(\mathrm{Ni}_{3} \mathrm{Nb}\right)$ and the Laves phases $\left(\mathrm{Fe}_{2} \mathrm{Nb}, \mathrm{Cr}_{2} \mathrm{Nb}\right)$ are formed from the $\mathrm{Nb}$-rich liquid in the later stage of the solidification, as can be understood from Figs. 1 and 2, and hence the liquid tends to flow down along the mush-zone towards the central portion of the ingots because of the larger specific gravity compared with that of the primary dendrites. As the result, the stream of the Nb-rich liquid probably turns into freckles in the ingots and also $\mathrm{Nb}$ is enriched in the central portion of them.

For comparison, the freckles formed in the ESR ingots of Waspaloy were examined in a similar way. Waspaloy is one of the well-known wrought nickel-based superalloys. Fig. 8 shows the chemical compositions of a specimen cut from an ESR ingot of Waspaloy in which 
the freckles existed. The meaning of the marks in the figure is the same as used in Fig.6. From Fig.8, it was evident that Ti was deficient in the central-portion. Also, both $\mathrm{Ti}$ and $\mathrm{Al}$ were significantly enriched in the freckle-portion. Similarly to the case of Inconel 718, the freckle formation in Waspaloy can be elucidated on the basis of the solidification sequence. For Waspaloy, it was reported that the solidification products were only MC carbides and the $\gamma^{\prime}\left(\mathrm{Ni}_{3}(\mathrm{Al}, \mathrm{Ti})\right)$ phase[10], and hence the residual liquid existing in the later stage of solidification will become Al-rich and Ti-rich, because the primary phase of solidification is the $\gamma$ phase. Therefore, the residual liquid has a smaller specific gravity than the primary dendrites, resulting in the flowing-up along the mushy-zone towards the surface portion. As the result, the stream of the liquid is considered to turn into the freckles in Waspaloy, as shown in Fig.9. In addition, $\mathrm{Zr}$ was slightly higher in the freckle portion as shown in Fig8. This may be due to the formation of $\mathrm{ZrC}$ carbide which has also a smaller specific gravity than the primary dendrite.

\section{Conclusions}

The microalloying effect of $\mathrm{Mo}, \mathrm{Nb}, \mathrm{Ti}, \mathrm{Al}$ and $\mathrm{C}$ on the solidification microstructures of Inconel 718 was examined by means of differential thermal analysis and microstructural observations. The results are summarized as follows; (1) the amount of MC carbide increased in the grain boundaries by the $\mathrm{C}$ addition, (2) the amount of Laves phase increased remarkably by the $\mathrm{Nb}$ addition, (3) the dark area, in which both the $\gamma^{\prime}$ and the $\gamma$ " phase precipitate, increased but the amounts of the MC carbide and the Laves phase decreased by the Ti addition. In addition, an explanation was given for the mechanism of the freckle formation in ESR ingots of Inconel 718 and Waspaloy.

\section{References}

1. S.T.Wolodek and R.D.Field, "The structure of Rene' $220 \mathrm{C}$ ", Proceedings of International Symposium on Superalloys 1992, AIME, (1992), 477-486.

2. M. Kaufman and A.E. Palty, "The Phase Structure of Inconel 718 and 702 Alloys," Transactions of the Metallurgical Society of AIME, 221(1961),1253-1262.

3. H.L. Eiselstein, "Metallurgy of a Columbium-Hardened Nickel-Chromium-Iron Alloy," American Society Testing Materials Spec. Tech. Report, 369(1965), 62-79.

4. D.F. Paulonis, J.M. Oblak and D.S. Duvall, "Precipitation in Nickel-Bse Alloy 718," Transaction of the ASM, 62(1969), 611-622.

5. J.M. Oblak, D.F. Paulonis and D.S. Duvall, "Coherency Strengthening in Ni Base Alloys Hardened by $\mathrm{DO}_{22} \gamma^{\prime \prime}$ Precipitates," Metallurgical Transactions, 5(1974), 143-153.

6. Ya-fang Han, P.Deb and M.C. Chaturvedi, "Coarsening Behaviour of $\gamma$ '- and $\gamma$-Particles in Inconel Alloy 718," Metal Science, 16(1282), 555-561.

7. M.C. Chaturvedi and Ya-fang Han, "Strengthening Mechanism in Inconel 718 Superalloy," Metal Science, $17(1983), 145-149$.

8. A.S. Ballantyne and A. Mitchell, "The Prediction of Ingot Structure in VAR/ESR Inconel 718," Sixth International Vacuum Metal Conference, San Diego Calif., (1979), 599-623.

9. G.A. Knorovsky, M.J. Cieslak, T.J. Headley, A.D. Romig.Jr and W.F. Hammetter, "Inconel 718 : A Solidification Diagram," Metallurgical Transactions A, 20A(1989), 2149-2158.

10. Y.Murata, M.Morinaga, N.Yukawa, H.Ogawa and M.Kato, "Solidification and Precipitation Behaviour of Inconel 718 and Waspaloy", Proceedings of The 1st Pacific Rim International Conf. on Advanced Materials and Processing (PRICM-1), Eds. Changxu Shi et al., TMS, Pennsylvania, (1992), 269-274.

11. N.Yukawa, Y.Murata and T.Noda, "Analysis of Solidification Behaviour and Alloy Design of a Nickel-Base Superalloy, IN-100," Proceedings of International Symposium on Superalloys 1984 , AIME, (1984), 83-93. 